\title{
Development and utilization of implantable cardiac monitors in free-ranging American black and Eurasian brown bears: system evolution and lessons learned
}

\author{
Timothy G. Laske ${ }^{1 *}$, Alina L. Evans ${ }^{2}$ (D), Jon M. Arnemo ${ }^{2,3}$, Tinen L. Iles ${ }^{1}$, Mark A. Ditmer ${ }^{4}$, Ole Fröbert ${ }^{5}$,
}

David L. Garshelis ${ }^{6}$ and Paul A. laizzo ${ }^{1}$

\begin{abstract}
Biologgers can be used to monitor both human and animal physiology and behaviors, activity patterns, and/or environmental stressors. Monitoring of heart rates and rhythms, respiratory patterns, and activity in free-ranging bears can provide unique insights into physiological mechanisms. Such research can also influence the conservation of wildlife, the management of human-wildlife conflicts, and potentially human medicine. Here we describe our experiences with the development and utilization of three generations of implantable biologgers in American black and Eurasian brown bears (Ursus americanus and Ursus arctos arctos). These devices have enabled novel investigations into the underlying mechanisms for winter survival, including the discovery of an extreme respiratory sinus arrhythmias that acts to conserve energy while providing adequate circulation to maintain alertness (i.e.,"fight or flight" behaviors). Extreme variations in heart rate have also been documented, including a $33.8 \mathrm{~s}$ asystole and a 261 beats/min sinus tachycardia in black bears and a $39.4 \mathrm{~s}$ asystole and a 240 beats/min sinus tachycardia in brown bears. Long-term data recording has also identified annual trends in heart rates and activity in both species. Combining physiological data with concurrent GPS collar locations provided insights into the impacts of human and environmental stressors (hunting, predation by other bears, road crossings, drones), which would not have been apparent through spatial data analysis alone. More recently, short-range wireless telemetry has allowed for real-time streaming of data via telemetry stations placed in remote den locations. Future iterations include transponders for biomonitoring and as an early warning system to aid in the prevention of poaching in free-ranging animals. In this review, we discuss the primary experimental capabilities of the current and next-generation systems. We highlight device evolution in terms of new physiological measurements (e.g., temperature, activity, impedance, posture), increased data storage capacity, improved wireless capabilities, and miniaturization to reduce the invasiveness of implantation procedures. These biologgers are now being applied to other species, and the possibilities seem limitless as technologies continue to advance.
\end{abstract}

Keywords: Autonomic nervous system, Conservation, Heart rate, Hibernation, Respiratory sinus arrhythmia, Stress, Ursus, Wildlife

\footnotetext{
*Correspondence: lask0033@umn.edu; tim.g.laske@medtronic.com

1 Department of Surgery, University of Minnesota, B172 Mayo, MMC 195,

420 Delaware Street SE, Minneapolis, MN 55455, USA

Full list of author information is available at the end of the article
} 


\section{Background}

American black and brown bears (Ursus americanus and Ursus arctos) are remarkable mammals, alternating between short active periods and long periods of hibernation, and are able to manage extreme variations in climate and food availability via physiological adaptations [1-4]. To manage and conserve both wild and captive bear populations, researchers have strived to understand these animals' underlying physiological behaviors, as well as the impact of human-bear conflicts, destruction and alteration of habitat, and climatic variability [5-12]. In addition, elucidation of the mechanisms underlying the unique physiology of these animals during hibernation has been pursued in search of new therapeutic approaches in human medicine [13-15].

Radiotelemetry collars have been deployed for the past five decades and have provided the principal means of studying the interactions of free-ranging animals within their environment [16-20]. Bears are ideal study subjects for physiological monitoring because they have long life spans and large home ranges (and hence encounter various, measurable environmental stimuli, both natural and human related). In addition, they exhibit extreme variations in their physiologies in response to food availability and seasonal changes, including hibernating for up to 6-7 months each year. Bears are also of such a size that they can readily be fitted with radio collars that can record GPS (global positioning system) locations. These GPS locations, and associated movements, can be matched to changes in heart rates (HRs) and/or other physiological parameters, thus allowing correlation between physiological changes and environmental factors [21]. In addition to transmission from remote telemetry stations, physiological information will soon be transmitted in real time from free-ranging animals using custom designed radio collars linked with Bluetooth ${ }^{\mathrm{TM}}$ technologies [22]. Despite improvements, the performance and integrity of these devices may still be compromised by the animals themselves (e.g., slipping off or damaging collars or the elicitation of a dramatic foreign body response to implantable devices) [23, 24].

In this review, we focus on our collective experiences with biologger devices utilized for both black and brown bear field investigations. We describe our experiences in cardiac monitoring, including the development of novel devices and the use of both standard and custom versions of devices originally designed for human clinical use. In addition, we discuss the features and limitations of the various systems utilized and summarize unique data that we have recorded over the past two decades. A particular emphasis of this review was placed upon variations in HR occurring under natural conditions and during interactions with humans, human developments, and agricultural regions. This provided insight into changes in metabolic rate in response to human and environmental stressors [8, 25-30].

\section{Devices utilized}

A series of microelectronic biologger devices, originally developed for human clinical use, were modified and/ or utilized in free-ranging black and brown bears over the period of 1999-present (see Fig. 1 for a comparison of the configurations of the three generations of devices used). These devices included custom constructions utilizing some clinical components, unmodified clinical devices with and without custom telemetry stations, and custom software upgrades tailored to the needs of our field research.

Prior to implantations in our study animals, all devices were sterilized with ethylene oxide gas (ESS 3000 unit, Anderson, Haw River, NC, USA or Anaprolene AN74i 60 L, Andersen Europe, Kortrijk, Belgium). In Wyoming, Colorado, and Minnesota, American black bears were located in their winter dens, anesthetized (Telazol ${ }^{\circledR}$, tiletamine, and zolazepam), and temporarily extricated [31]. In Minnesota black bears, device implantations were also performed in the summer months (anesthetized with ketamine and xylazine). In Sweden, brown bears were anesthetized when active in summer, by darting from helicopters (mixture of tiletamine-zolazepam, and medetomidine with dosing adjusted for body

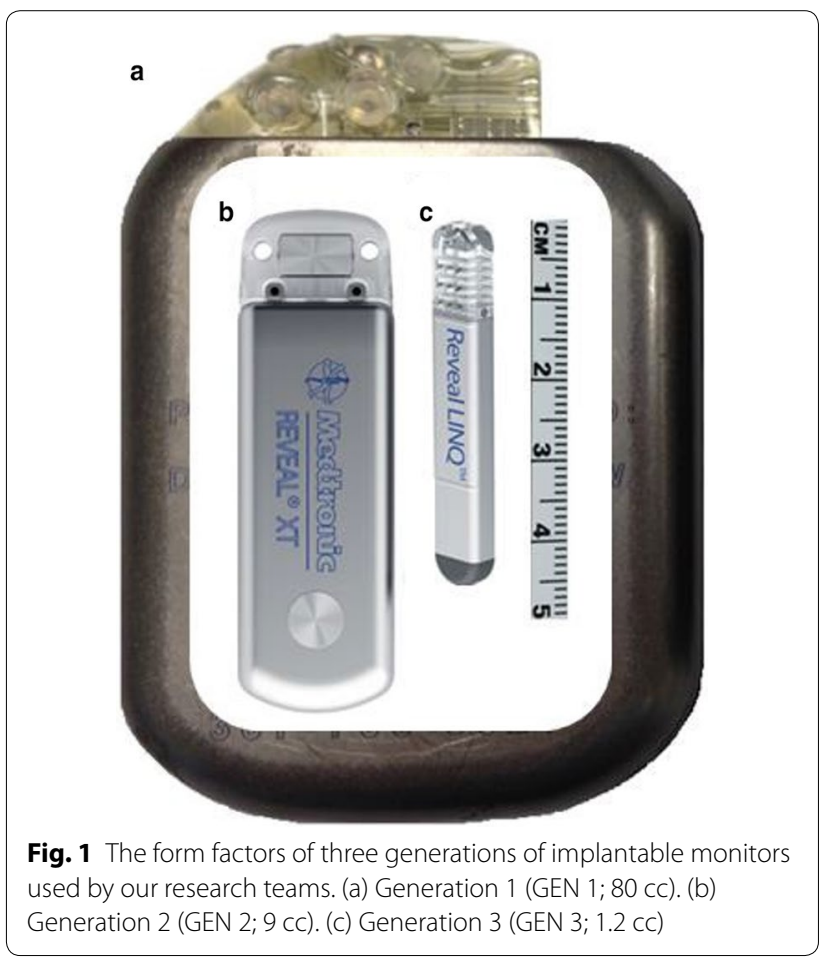


mass and time of year) [32, 33]. During handling, study devices were implanted or explanted and/or data were downloaded from previously implanted devices using short-range telemetry, or in later black bear studies, using custom telemetry stations.

\section{GEN 1}

The first-generation (GEN 1) devices were used in Wyoming and Colorado from 1999 to 2001 in black bears $(n=6)$. These devices were produced by modifying implantable cardioverter defibrillator devices designed for humans (Jewel Implantable Cardioverter Defibrillator, Medtronic, Inc., Minneapolis, MN, USA; Fig. 1a) [24, 31]. These devices had an $80 \mathrm{cc}$ volume, a $104 \mathrm{~h}$ recording capacity for wideband electrocardiograms collected from subcutaneously implanted electrodes (Sprint Model 6942 Lead, Medtronic, Inc., Minneapolis, MN, USA), and were programmable to allow duty cycling of recording intervals (typically $30 \mathrm{~s}$ of recording every $15 \mathrm{~min}$ ). In 1999, the device was implanted subcutaneously in the abdominal region with the electrodes placed in a subcutaneous region near the sternum. In 2000, the device was implanted in the peritoneal cavity with the electrodes adjacent to the diaphragm. Although these devices resulted in successful collection of broadband electrical data from a cohort of wild bears, including the novel discovery of an extreme respiratory sinus arrhythmia (RSA), we also unexpectedly observed a high foreign body rejection rate. Device rejection occurred in 5 of 6 study animals within 90 days post-implant during the winter months [31]. Further, through these experiences, we observed first-hand that black bears elicit rapid wound healing abilities during hibernation. More specifically, we found little or no evidence post-rejection as to the prior existence of implants due to tissue remodeling at the implant location [23, 24, 34, 35]. High rejection rates in our study, and another study using implanted telemetry devices in black bear cubs [35], led the authors to question the practicality of implanted devices in free-ranging bears. Subsequently, Nelson et al. [36] reported the successful deployment of modern, much smaller-sized, human clinical cardiac monitors in four captive brown bears. They recorded high-quality data and observed no device rejections in this cohort. Their work motivated us to revisit the use of these smaller-sized implantable data recorders that did not require implantable leads in our free-ranging cohorts of bears.

\section{GEN 2}

Generation 2 (GEN 2) devices were unmodified human clinical devices (2009-2012; $n=100$ devices deployed; $n=39$ black; and $n=33$ brown bears; Fig. 1b; Reveal ${ }^{\circledR}$ DX and XT; Medtronic, Inc., Minneapolis, MN, USA;
$9 \mathrm{cc} ; 8 \mathrm{~mm} \times 19 \mathrm{~mm} \times 62 \mathrm{~mm} ; 15 \mathrm{~g}$; 3-year recording life). Typically, GEN 2 devices were surgically implanted peristernally on the animal's left side between the muscle and subcutaneous fat, with the incision closed with sutures, using 2-0 absorbable suture (multifilament suture in the Minnesota black bears: Vycril ${ }^{\circledR}$ Polyglactin; Ethicon, Rome, Italy, and monofilament glycomer in Swedish brown bears: Biosyn Corporation, Carlsbad, California, USA, or PDS ${ }^{\circledR}$ II (polydioxanone) suture, Ethicon, Inc., Somerville, NJ). All device electronics were housed in hermetically sealed titanium cans. Electrocardiograms were recorded from the differential voltage measured between onboard electrodes (i.e., a titanium electrode housed in a polyurethane and silicone header and a region on the parylene-coated titanium can). A built-in single-axis accelerometer was utilized to detect the motion, and hence, the bear's relative activities were documented via movements of the thorax. Device programming and data retrieval were performed via transcutaneous telemetry using a programming system (CareLink Model 2090 Programmer with custom software Model SW007, Medtronic, Inc., Minneapolis, MN, USA; telemetry range of $5 \mathrm{~cm}$ ). Data collected included average daytime and nighttime HR, daily heart rate variability (HRV; standard deviation of beat-to-beat intervals in sinus rhythm (SDANN) using 5-min medians), and total daily activity in minutes. Automatically detected arrhythmias were recorded, but due to memory limitations, only the 30 most recent events were stored. Typically, older events were overwritten, and potentially some of these could have been the more interesting physiological events. This is not a typical clinical problem in humans, however, since patients contact their physician when a dysrhythmia occurs. In contrast, we frequently downloaded bear data only annually. Thus, we focused data collection on what we believed were the most relevant arrhythmias, including (1) ventricular tachycardias ( $\geq 176 \mathrm{bpm})$ and 2$)$ asystoles ( $\geq 4.5 \mathrm{~s})$. Interestingly, these employed algorithms were found to record periods of extreme RSA as potential episodes of atrial fibrillation, which is typically detected via variabilities within the ventricular HRs, and hence, this modality was disabled. Nevertheless, given the 3-year life and multi-year recording capability, GEN 2 units allowed the collection of trends in annual physiologies and behaviors (Fig. 2). These data were combined with GPS locations from radio collars to allow us to investigate both behavioral and physiological reactions to a multitude of environmental factors $[6,21,37]$.

A unique attribute of the DX version of the GEN 2 device ( $n=6$ black and $n=1$ brown bears) was that it was possible to capture a 15 -min continuous recording of an electrocardiogram (ECG). This option was 


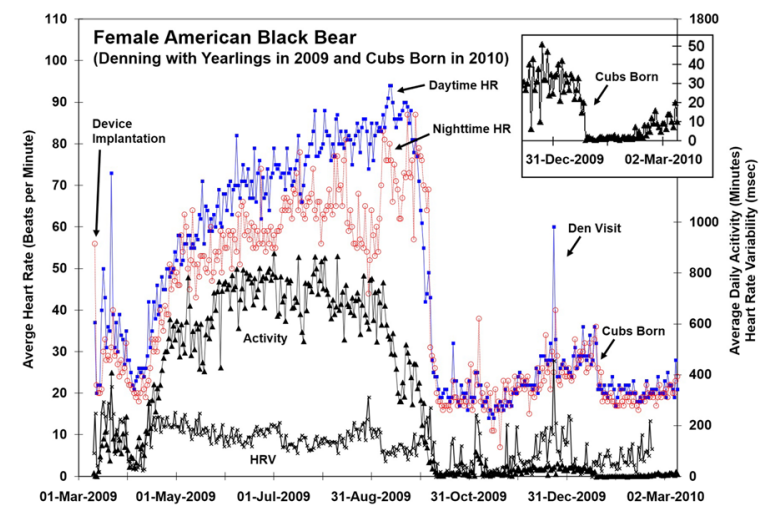

Fig. 2 Annual trends in heart rate (HR), activity, and heart rate variability (HRV) recorded from a female black bear in Minnesota denning with yearlings in 2009 and birthing cubs in January of 2010. These data were recorded with a Generation 2 (GEN 2) device with conventional human clinical software. A steady increase in $\mathrm{HR}$ and activity occurs through the spring with a sharp decrease in the fall prior to hibernation. A transient increase in HR and activity is seen just prior to parturition, with cessation of activity occurring immediately after (see inset)

triggered using an externally placed activator. We were interested in recording heart rhythm changes associated with our approach and immobilization. Although this feature has practical utility with captive animals and in human subjects, triggering the device typically took more than 15 min post-approach and immobilization. In only one instance were we able to initiate recording in less than $15 \mathrm{~min}$, but we found the device had been rejected and was lying inside the den. In all other situations, we recorded cardiac rhythms associated with tranquilization and anesthetic responses, but not approaches to the den.

Although these GEN 2 devices improved our ability to collect unique HR data, high rejection rates frequently occurred in our study of free-ranging black bears. Interestingly, in one 12-month period, we observed a rejection rate of $100 \%$ (December 2010March 2011, $n=18$ ), while in others seasons during the 2009-2012 timeframe rejection rates only averaged $49 \%(n=17 / 37)$ [6]. Due to the high rejection rate, we began implanting two devices per animal as a general practice, resulting in the retention of at least one device in 8 of 9 bears during the December 2012 den visits. In contrast, rejections of Reveal devices have been rare $(<8 \%)$ in free-ranging brown bears, even though similar implantation methods were utilized (7 rejections out of 83 implants from 2010 to 2017). Of these, seven lost devices and three remained in place for over 1 year before being rejected. Six of the rejected devices were replaced, of which two were subsequently rejected: one between 7 and 12 months from implantation, and the other between 1 and 2 years. The lower rejection rates in brown bears are consistent with the experience of Nelson et al. [36] for captive brown bears, perhaps suggesting a species variation. It is important to note that in many black bears we handled, we did not observe device rejection until 1 or 2 years after the initial implant; acute rejection immediately post-implantation was rare. This suggests that device rejection in both black and brown bear is related to a foreign body response rather than to acute inflammation or surgical technique.

\section{GEN 2: BearWare}

In 2012, custom software was deployed in the GEN 2 devices in both new and existing implanted devices (2012-2017; $n=140$ devices deployed; $n=42$ black and $n=56$ brown bears; BearWare, Medtronic Inc., Minneapolis, MN, USA). The BearWare increased sampling rates to improve our ability to correlate HRs and thoracic motions/activities with GPS locations in assessing the impact of short-term events (Table 1; Fig. 3). This new software enabled the recording of average HRs every 2 min and total activity every 15 min. BearWare also recorded the ten most extreme events for both asystoles and tachycardias, an important function since freeranging black and brown bears experience thousands of asystolic events $>4.5 \mathrm{~s}$ during winter [6]. Nonetheless, under-sensing of the ECG and over-sensing of electrical noise and/or t-waves during times of unusual activity resulted in some erroneous recordings.

\section{GEN 3}

The Reveal LINQ ${ }^{\mathrm{TM}}$ is being utilized as the GEN 3 device platform (2013 to present; Fig. 1c; Medtronic Inc., Minneapolis, MN, USA; $1.2 \mathrm{cc} ; 4.0 \mathrm{~mm} \times 7.2 \mathrm{~mm} \times 44.8 \mathrm{~mm}$; $2.4 \mathrm{~g})$. These biologgers are $99 \%$ smaller than GEN 1 and $87 \%$ smaller than GEN 2, function for 3 years, were implanted via an injection tool in the left peristernal region, and require only a single stitch to close the implant site. The first version of software was similar to the production GEN 2 (i.e., without BearWare), but had added temperature, impedance, and a wireless capability that enabled remote web-based monitoring $(n=28$ systems deployed over 5 winters monitoring 21 different black bears; Fig. 4). This ability for remote data transmission reduced limitations associated with device memory, thus allowing a dramatic increase in the quantity of data recorded and also alerted the team to extremes in HR associated with natural and human disturbances [22, 38]. Telemetry stations are impractical for brown bears since they typically relocate upon disturbance of their dens [7]. 
Table 1 Summary of the device generations and select findings

\begin{tabular}{|c|c|c|c|}
\hline Device & Features & Species/usage & Findings \\
\hline GEN 1 & $\begin{array}{l}80 \mathrm{cc} \\
104 \text { h recording capacity } \\
\text { Programmable to allow duty cycling } \\
\text { of recording intervals }\end{array}$ & $\begin{array}{l}\text { Ursus americanus (Colorado and } \\
\text { Wyoming, USA) } \\
n=6 \text { devices in } 6 \text { bears }\end{array}$ & $\begin{array}{l}\text { Longest asystole }=13.3 \mathrm{~s} \\
\text { Extreme RSA identified } \\
\text { Avg HR increased when electromyo- } \\
\text { grams (EMGs) were present } \\
\text { Longest duration of data col- } \\
\text { lection }=68 \text { days (HR } \\
\text { Avg }=13.5 \pm 3.8 \text { bpm) } \\
\text { No significant changes in the QRS or QT } \\
\text { intervals during hibernation } \\
\text { Rate dependence of QT interval lost } \\
\text { during hibernation } \\
\text { Extreme foreign body response }\end{array}$ \\
\hline \multirow[t]{2}{*}{ GEN 2} & $\begin{array}{l}9 \mathrm{cc} \\
\text { 3-year battery life } \\
\text { Records daytime HR, nighttime HR, } \\
\text { activity, and episodes with ECGs }\end{array}$ & $\begin{array}{l}\text { Ursus americanus (Minnesota, USA) } \\
n=65 \text { devices in } 39 \text { bears }\end{array}$ & $\begin{array}{l}\text { Longest asystole }=14.4 \mathrm{~s} \\
\text { Maximum HR=261 bpm (bear shot by } \\
\text { hunter) } \\
\text { Respiratory rate increased as investiga- } \\
\text { tors approached the den, serving to } \\
\text { increase the average HR } \\
\text { Anesthesia eradicated the RSA }\end{array}$ \\
\hline & & $\begin{array}{l}\text { Ursus arctos (Sweden) } \\
n=35 \text { devices in } 33 \text { bears }\end{array}$ & $\begin{array}{l}\text { Maximum HR=240 bpm (07 Oct } 13 \\
\text { and } 19 \text { Oct 13; 2-year-old female) } \\
\text { Longest asystole }=15.8 \text { s (26-Feb-2013; } \\
\text { 2-year-old female) }\end{array}$ \\
\hline \multirow[t]{2}{*}{ GEN 2 with BearWare } & $\begin{array}{l}\text { GEN } 2 \text { features with } \\
\text { Avg HR every } 2 \text { min } \\
\text { Activity at } 15 \text {-min intervals } \\
\text { ECGs for the } 10 \text { extremes for tachycar- } \\
\text { dias and asystoles }\end{array}$ & $\begin{array}{l}\text { Ursus americanus (Minnesota, USA) } \\
n=69 \text { devices in } 42 \text { bears }\end{array}$ & $\begin{array}{l}\text { Longest asystole }=33.8 \mathrm{~s}(03-\text { Mar-2015; } \\
\text { 4-year-old female) } \\
\text { Maximum HR=261 bpm (02-Sep-2010; } \\
\text { adult female) }\end{array}$ \\
\hline & & $\begin{array}{l}\text { Ursus arctos (Sweden) } \\
n=71 \text { devices in } 56 \text { bears }\end{array}$ & $\begin{array}{l}\text { Longest asystole }=39.4 \mathrm{~s} \text { (03-Nov-2016; } \\
31 / 2 \text {-year-old female) } \\
\text { Maximum HR=222 bpm (07-May- } \\
\text { 2014; 2-year-old female) }\end{array}$ \\
\hline GEN 3 with Telemetry Stations & $\begin{array}{l}\text { GEN } 2 \text { features with } \\
1.2 \text { cc } \\
\text { 3-year battery life } \\
\text { Temperature } \\
\text { Impedance } \\
\text { Wireless capability }\end{array}$ & $\begin{array}{l}\text { Ursus americanus (Minnesota, USA) } \\
n=29 \text { devices in } 21 \text { bears with } 28 \\
\text { telemetry stations deployed }\end{array}$ & $\begin{array}{l}\text { Demonstrated feasibility of remote } \\
\text { web-based monitoring of bears in } \\
\text { the wild } \\
\text { Cessation of long sinus pauses during } \\
\text { parturition } \\
\text { Subcutaneous impedance decreased } \\
\text { during hibernation }\end{array}$ \\
\hline GEN 3 with B-Ware & $\begin{array}{l}\text { GEN } 3 \text { and BearWare features with } \\
\text { Posture } \\
\text { Rejects asystoles }>60 \text { s and tachycar- } \\
\text { dias }>275 \text { bpm }\end{array}$ & $\begin{array}{l}\text { Ursus americanus (Minnesota, USA) } \\
n=10 \text { devices in } 10 \text { bears }\end{array}$ & Results pending \\
\hline
\end{tabular}

$A v g$ average, $H R$ heart rate, $R S A$ respiratory sinus arrhythmia, bpm beats per minute, \pm standard deviation

\section{GEN 3 software upgrades}

Several software versions have been used with GEN 3 devices. The first version included recording and transmitting temperatures, impedances, and beat-to-beat HRs over an 8-min period. In December 2016, the capability to transmit posture, average $\mathrm{HR}$, and activity data in 20-min intervals was added, but this necessitated a reduced data collection interval from 400 to 90 days. In the summer of 2017, further modifications were made to GEN 3 software for use in free-ranging animals $(n=10$ deployed in 10 black bears; B-Ware, Medtronic Inc., Minneapolis, MN, USA). This software version collected 2-min average HR and total activity every $15 \mathrm{~min}$, with a 400-day recording interval. In addition, to prevent the capture of non-physiological extremes relating to oversensing and under-sensing, these devices reject any asystole $>60 \mathrm{~s}$ or tachycardia $>275 \mathrm{bpm}$. We also employed a Reveal LINQ ${ }^{\mathrm{TM}}$ device positioned over the frontal cortex, to record and transmit EEG (electroencephalogram) data from a black bear during hibernation $(n=1)$. Signal qualities of these recordings were excellent, but are still being interpreted.

\section{Select findings}

In addition to the extreme RSA, the evolution of device technologies has led to numerous findings relating to 


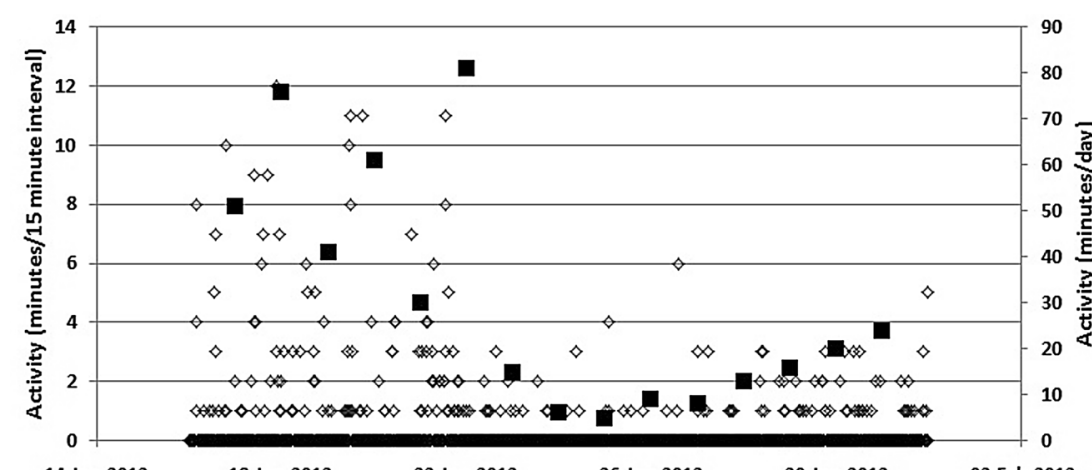

$\diamond$ BearWare Activity

Daily Activity

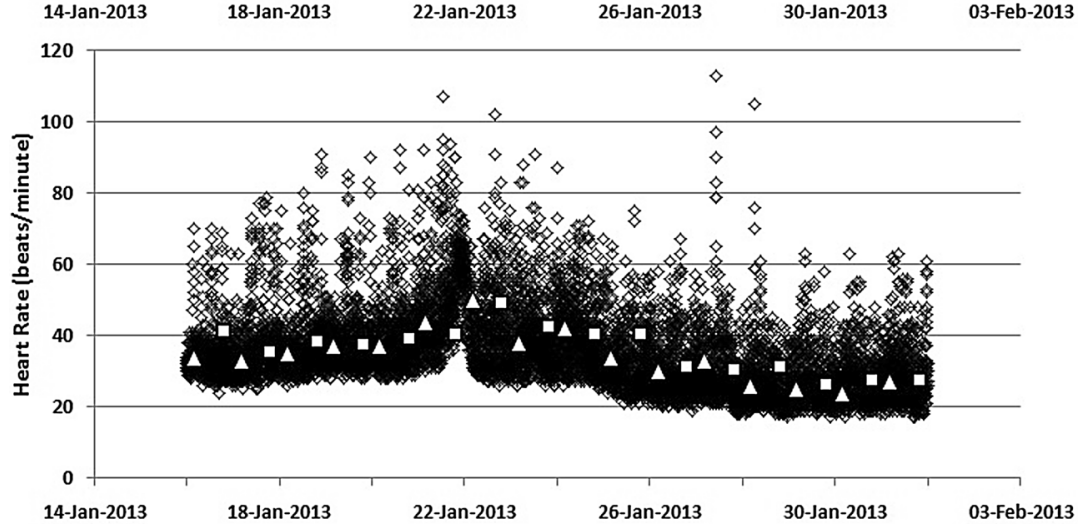

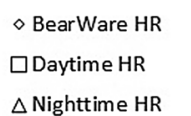

$\triangle$ Nighttime HR

Fig. 3 Activity data (top panel) and average heart rates (HRs; bottom panel) for the Generation 2 device (GEN 2) with and without the BearWare software patch recorded from a pregnant female black bear hibernating in northern Minnesota. At the time of parturition (22-Jan-2013) the average HR can be seen to acutely increase with a marked reduction in activity in the subsequent days

both normal physiologic responses to human interactions and to environmental stressors. Although a hibernating bear's heart behaves similarly to a failing human heart (low HRs, asystoles, and reduced cardiac output), no signs of heart failure or dysfunctions have been observed [39]. High degrees of HRVs were recorded in both bear species (Fig. 2), with minimum levels during hibernation. This may seem counterintuitive given the extreme RSA that exists during hibernation, but since the computational methods used by these devices (SDANN) evaluate changes in the median HR at 5-min intervals, minimal variabilities occur in winter since RSAs remain consistent. Impacts of our presence during hibernation are shown in Figs. 5 and 6 . Under natural conditions, we observed respiratory rates as low as 1-3 breaths/ min during hibernation, with both HRs and respiration rates accelerating as we approached dens. We believe that these hyper-ventilatory behaviors are adaptive to quickly sustain elevated HRs (overriding the RSA) versus being stress or fear responses [6]. Perhaps such monitoring can help determine adequate buffer distances which minimize human disturbance.

By combining data from implanted cardiac monitors with concurrent locational data, we have identified that
HRs of black bears in fall began to decline, on average, 2 weeks before bears demonstrated reduced movement. We posit that this metabolic change enables more efficient fat storage preparatory to hibernation [21]. We have also observed reductions in subcutaneous impedances throughout the winter, which would be expected from both fat loss and dehydration [40]. Brown bears began decreasing activity 25 days prior to den entry, their HRs 24 days before, and body temperatures 13 days before [37]. Further, it has been shown that summer active black bears exhibited stress responses when crossing open agricultural fields, but were at ease when feeding within dense fields of corn. In fall, when this same population of bears was rapidly gaining body mass and growing thick fur, HRs slowed disproportionately relative to movements with higher temperatures, likely indicative of attempts to prevent overheating [19].

In a controlled study designed to investigate the potential effects of unmanned aerial vehicle flights (UAVs; "drones") near wild black bears, we observed strong physiological responses (HRs rising as much as $123 \mathrm{bpm}$ over baseline), but infrequent behavioral changes (movement away from the UAV). This observation underscores the importance of considering the impacts UAV have on 


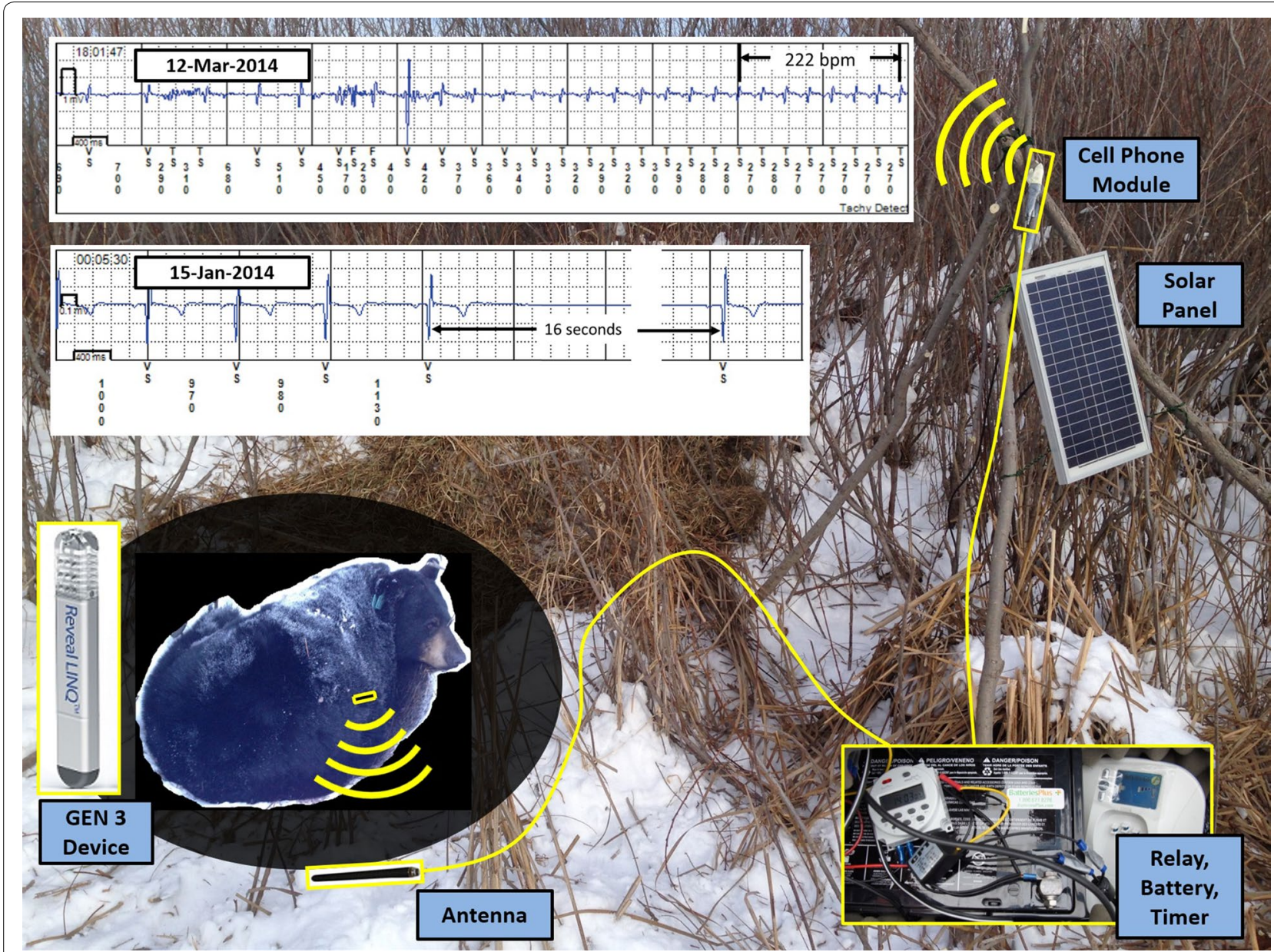

Fig. 4 System configuration for a Generation 3 (GEN 3) device with a telemetry station. The sample electrocardiograms (ECGs) shown are from a female black bear in Minnesota hibernating with yearlings. Episodes shown include an episode with a $16 \mathrm{~s}$ asystole and a 222 bpm (beat/min) sinus tachycardia that was believed to be related to disturbance of the den by the landowners

wildlife when developing regulations and best scientific practices [41]. We took a similar approach to assess the impacts on free-ranging bears of crossing or being near, roadways [42]. However, unlike the UAV study, the exact timing of when bears were near roadways was not available. A study limitation became the 112-min average recording interval for GPS coordinates (required to conserve battery depletion). To overcome this, we compared maximum HRs between periods with and without road crossings and found that road crossings were associated with average increases of only $13 \mathrm{bpm}$, with these elevations occurring at distances of 73-183 m, whether or not the road was crossed. We concluded that elevated HRs were associated with increased vigilance when navigating this human-altered landscape.

Finally, as the level of sophistication of implantable biotelemetry increases, our ability to document extreme physiological responses will improve. Example ECGs are shown in Fig. 7 with unique situations displayed, including bear-on-bear predation, a bear that was legally shot by a hunter, a bear hit and killed by an automobile, and the most extreme asystole yet captured by the devices (39.4 s). A summary of the generations of devices and the physiological findings associated with each generation of device and software are presented in Table 1.

\section{Conclusions}

Modern implantable physiological monitors (aka biologgers) and incorporated custom software applications, such as BearWare and B-Ware, will provide unique opportunities for scientists to characterize both the natural physiologies of bears and provide insight regarding human impacts. Although this has enabled new opportunities in our bear research, limitations exist due to moderate foreign body rejection rates in free-ranging black bears (less frequent in brown bears), as well as current 


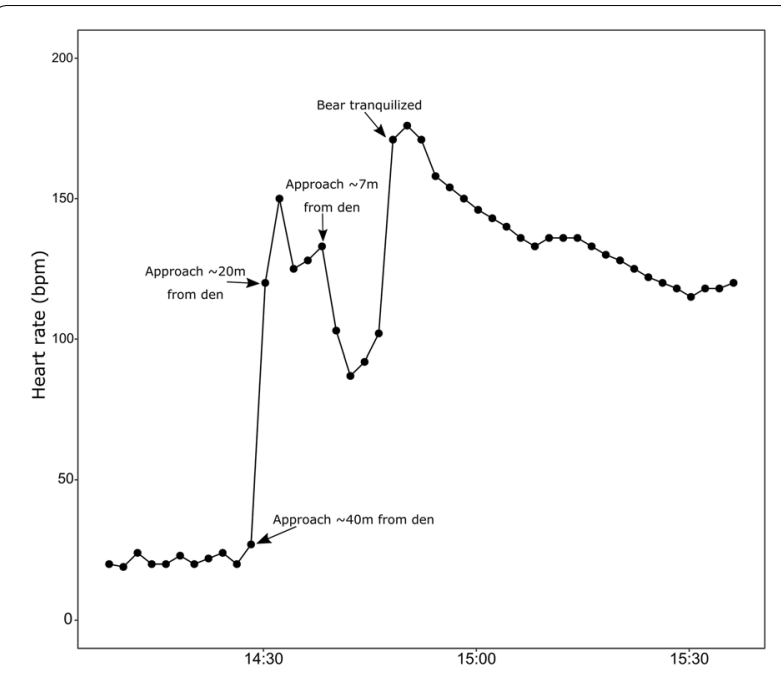

Fig. 5 Heart rate (HR) changes occurring during our approach to a black bear den in Minnesota during March of 2014. These data were collected using a Generation 2 (GEN 2) device with the BearWare software patch. An increase in heart rate occurred as the team moved to within $\sim 40$ meters of the den. The HR decreased following tranquilization as the anesthetic agent took effect

limitations on device memory. Data so far indicate that the Reveal LINQ ${ }^{\mathrm{TM}}$ is associated with reduced rejection rates in both species due to reduced device volume.
Regardless, as technologies continue to advance, these small devices will have increasing monitoring capabilities. Further, incorporation of short-range wireless telemetry has provided new avenues for data transfer, thus circumventing potential limitations in device memory capacities. We anticipate that in the future, implantable wireless devices will communicate directly with radio collars which will transmit detailed physiological data. This advancement will both increase data quantity and alert authorities/researchers when an extreme physiological situation arises that might be associated with an animal in distress. For example, this may allow for improved monitoring by wildlife managers to prevent poaching [43]. Nevertheless, wireless transmissions increase power consumption so improvements in battery longevities will be needed.

We continue to explore new algorithms for the characterizations of HRV and have already added additional sensing capabilities beyond HR and activity, including body temperatures, calibrated body positions, and local tissue impedances. Increased memory and data transmission will allow for the measurements of respiratory rates, thus enabling the potential for calculating of metabolic rates. Such modifications will increase our ability to monitor and manage animals in the wild. Finally, while we have largely focused on extreme excursions in HRs, we are continuing to prioritize associations between $\mathrm{HR}$

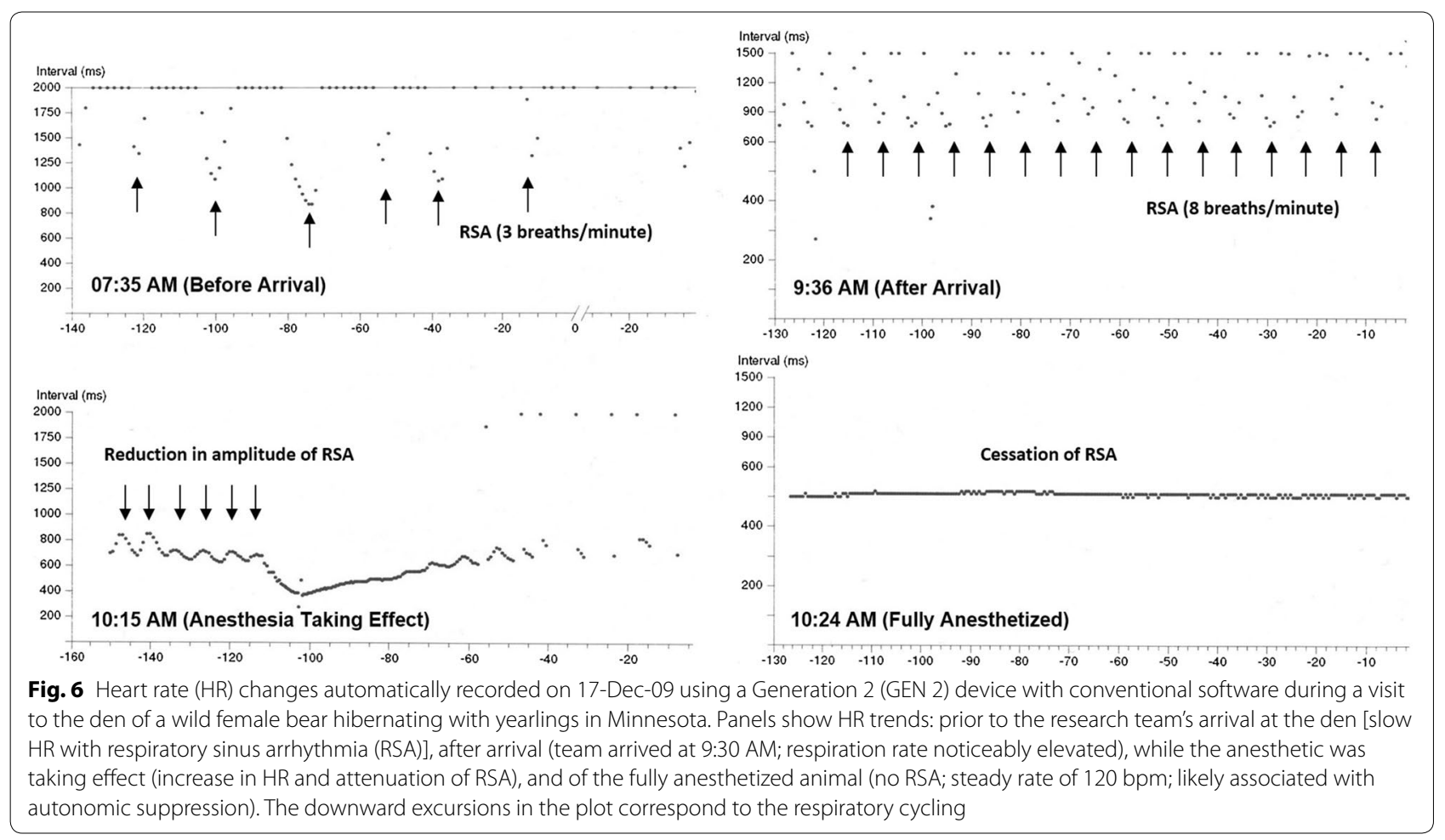




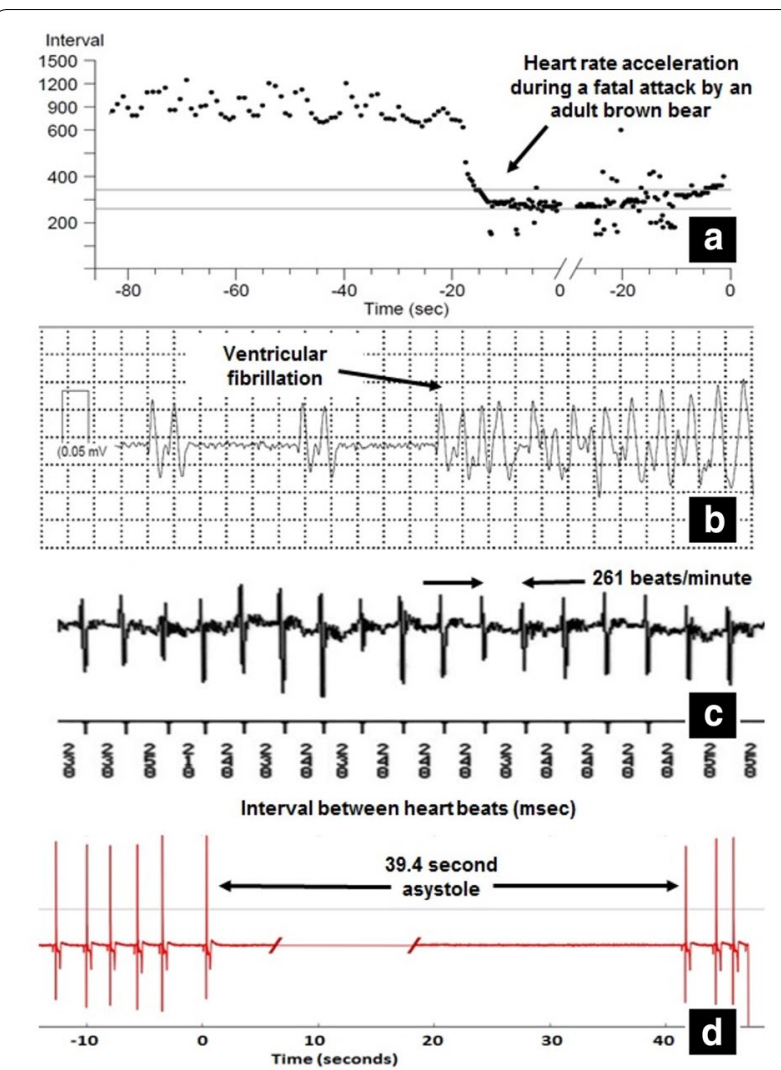

Fig. 7 Sample episode recordings. a Recording from a yearling brown bear in Sweden killed by another brown bear showing heart rate acceleration associated with the attack (26-Feb-2014). b Ventricular fibrillation recorded from an adult female black bear that was hit by a car in Minnesota (31-Jul-2017). c Electrocardiogram of an adult female black bear legally shot by a hunter in Minnesota (up to 261 beats/min, 02-Sep-2010). d Asystole recorded from a 3 $1 / 2$-year-old female brown bear during hibernation in Sweden (39.4 s, 03-Nov-2016). a, b, d Were recorded with the Generation 2 (GEN 2) device with the BearWare software patch. $\mathbf{c}$ Used GEN 2 with conventional software

and numerous environmental situations by pairing cardiac data with GPS locations.

As we investigate new device and software platforms, we will continue to characterize the physiologies of both black and brown bears $[13-15,31,39]$. Our research has clearly benefitted from advances in medical technologies, and in turn, we hope that someday insights from bear physiology may benefit humans.

\section{Authors' contributions}

TL led manuscript preparation. Details of individual research contributions of authors can be identified through the literature cited in this review. All authors read and approved the final manuscript.

\section{Author details}

${ }_{1}^{1}$ Department of Surgery, University of Minnesota, B172 Mayo, MMC 195, 420 Delaware Street SE, Minneapolis, MN 55455, USA. ${ }^{2}$ Department of Forestry and Wild life Management, Faculty of Applied Ecology and Agricultural
Sciences, Inland Norway University of Applied Sciences, Campus Evenstad, 2418 Elverum, Norway. ${ }^{3}$ Department of Wild life Fish and Environmental Studies, Faculty of Forest Sciences, Swedish University of Agricultural Sciences, 90183 Umeå, Sweden. ${ }^{4}$ Department of Fisheries, Wildlife and Conservation Biology, University of Minnesota, St. Paul, MN 55108, USA. ${ }^{5}$ Department of Cardiology, Faculty of Health, Örebro University, Örebro, Sweden. ${ }^{6}$ Minnesota Department of Natural Resources, 1201 E Hwy 2, Grand Rapids, MN 55744, USA.

\section{Acknowledgements}

Black Bear Research: Field work in Wyoming and Colorado was led by Henry Harlow of the University of Wyoming. Assistance with Minnesota fieldwork was provided by Karen Noyce and Brian Dirks of the Minnesota Department of Natural Resources. Brown Bear Research: We are grateful to Sven Brunberg for bear handling and logistics and to Lena Buske and Peter Linde for providing training and participating in the implantations of the first DX devices in Sweden. Technical assistance with the Reveal and Reveal LINQ ${ }^{\mathrm{TM}}$ devices was provided by Brian Lee, Eric Zhao, Grant Neitzell, Spencer Hurd, Paul Krause, Traci Washburn, David Washburn, Paul Solheim, Scott Hansohn, Kathryn Chang, and Scott Hawkinson of Medtronic. Assistance with manuscript formatting was provided by Monica Mahre. This work was supported by the Minnesota Department of Natural Resources and the University of Minnesota's Institute for Engineering in Medicine and Department of Surgery. The Scandinavian Brown Bear Research Project is funded primarily by the Norwegian Environmental Agency, the Swedish Environmental Protection Agency, and the Research Council of Norway. All cardiac monitors were donated by Medtronic.

\section{Competing interests}

Timothy G. Laske is an employee, and Paul A. laizzo is a consultant to Medtronic. The devices utilized are not available for sale for veterinary or wildlife applications.

\section{Availability of data and materials}

The datasets used and/or analyzed during the current study are available from the corresponding author on reasonable request.

\section{Consent for publication}

Not applicable.

\section{Ethics approval and consent to participate}

Black bear studies were reviewed by the University of Minnesota's Animal Care and Use Committee. Brown bears studies were conducted with approval of the Swedish Ethical Committee on animal research (C18/15) in compliance with Swedish laws and regulations.

\section{Funding}

Black Bear Research: This work was supported by the Minnesota Department of Natural Resources and the University of Minnesota's Institute for Engineering in Medicine and Department of Surgery. Brown Bears Research: Grants from the Norwegian Directorate for Nature Management, Nordforsk (project no. 44042) and the Lundbeck Foundation (grant nr R126-2012-12408). The Scandinavian Brown Bear Research Project is funded by the Swedish Environmental Protection Agency, the Norwegian Directorate for Nature Management, the Swedish Association for Hunting and Wildlife Management, WWF Sweden and the Research Council of Norway. All cardiac monitors were donated by Medtronic.

\section{Publisher's Note}

Springer Nature remains neutral with regard to jurisdictional claims in published maps and institutional affiliations.

Received: 25 March 2018 Accepted: 11 September 2018 Published online: 29 September 2018

\section{References}

1. Nelson R. Black bears and polar bears-still metabolic marvels. Mayo Clin Proc. 1987;62:850-3. 
2. Harlow HJ, Lohuis T, Anderson-Sprecher RC, Beck TDI. Body surface temperature of hibernating black bears may be related to periodic muscle activity. J Mammal. 2004;85:414-9.

3. Pelton MR. Black bear (Ursus americanus). In: Feldhamer GA, Thompson BC, Chapman JA, editors. Wild mammals of North America: biology, management, and conservation. 2nd ed. Baltimore: The Johns Hopkins University Press; 2003. p. 547-55.

4. Nelson OL, Robbins CT. Cardiovascular function in large to small hibernators: bears to ground squirrels. J Comp Physiol B. 2015;185:265-79.

5. Linnell JDC, Swenson JE, Andersen R, Barnes B. How vulnerable are denning bears to disturbance? Wildl Soc Bull. 2000;28:400-13.

6. Laske TG, Garshelis DL, laizzo PA. Monitoring the wild black bear's reaction to human and environmental stressors. BMC Physiol. 2011;11:13.

7. Evans AL, Singh NJ, Fuchs B, Blanc S, Friebe A, Laske TG, Frobert O, Swenson JE, Arnemo JM. Physiological reactions to capture in hibernating brown bears. Conserv Physiol. 2016;4:cow061.

8. Bourbonnais ML, Nelson TA, Cattet MR, Dairmont CT, Stenhouse GB. Spatial analysis of factors influencing long-term stress in the grizzly bear (Ursus arctos) population of Alberta, Canada. PLoS ONE. 2013;8:e83768.

9. Laske TG, laizzo PA, Garshelis DL. Six years in the life of a mother bearthe longest continuous heart rate recordings from a free-ranging mammal. Sci Rep. 2017;7:40732.

10. Wikelski M, Cooke SJ. Conservation physiology. Trends Ecol Evol. 2006;21:38-46.

11. Cooke SJ, Blumstein DT, Buchholz R, Caro T, Fernandez-Juricic E, Franklin CE, Metcalfe J, O'Connor CM, St. Clair CC, Sutherland WJ, Wikelski M. Physiology, behavior, and conservation. Physiol Biochem Zool. 2014;87:1-14.

12. Wilmers CC, Nickel B, Bryce CM, Smith JA, Wheat RE, Yovovich V. The golden age of bio-logging: how animal-borne sensors are advancing the frontiers of ecology. Ecology. 2015;96:1741-53.

13. Donahue SW, McGee ME, Harvey KB, Vaughan MR, Robbins CT. Hibernating bears as a model for preventing disuse osteoporosis. J Biomech. 2006:39:1480-8.

14. Berg von Linde M, Arevström L, Fröbert O. Insights from the den: how hibernating bears may help us understand and treat human disease. Clin Transl Sci. 2015;8:601-5.

15. Lohuis TD, Harlow HJ, Beck TD, laizzo PA. Hibernating bears conserve muscle strength and maintain fatigue resistance. Physiol Biochem Zool. 2007:80:257-69.

16. Nelson OL, McEwen MM, Robbins CT, Felicetti L, Christensen WF. Evaluation of cardiac function in active and hibernating grizzly bears. J Am Vet Med Assoc. 2003;223:1170-5.

17. Folk GE, Folk MA, Minor JJ. Physiological condition of three species of bears in winter dens. Bears Biol Manag. 1972;2:107-24.

18. Harlow HJ, Lohuis T, Beck TD, laizzo PA. Muscle strength in overwintering bears. Nature. 2001;409:997.

19. Tøien $\varnothing$, Blake J, Edgar DM, Grahn DA, Heller HC, Barnes BM. Hibernation in black bears: independence of metabolic suppression from body temperature. Science. 2011;331:906-9.

20. Tinker DB, Harlow HJ, BeckTD. Protein use and muscle-fiber changes in free-ranging, hibernating black bears. Physiol Zool. 1998;71:414-24.

21. Ditmer MA, Garshelis DL, Noyce KV, Laske TG, laizzo PA, Burk TE, Forester JD, Fieberg JR. Behavioral and physiological responses of American black bears to landscape features in an agricultural region. Ecosphere. 2015 https://doi.org/10.1890/es14-00199.1.

22. Laske TG, Garshelis DL, laizzo PA. Big data in wildlife research: remote web-based monitoring of hibernating black bears. BMC Physiol. 2014;14:13

23. laizzo PA, Laske TG, Harlow HJ, McClay CB, Garshelis DL. Wound healing during hibernation by black bears (Ursus americanus) in the wild: elicitation of reduced scar formation. Integr Zool. 2012;7:48-60.
24. Laske TG, Harlow HJ, Werder JC, Marshall MT, laizzo PA. High capacity implantable data recorders: system design and experience in canines and denning black bears. J Biomech Eng. 2005;127:964-71.

25. Bridges PK, Jones MT, Leak D. A taxonomic study of physiological responses to a psychological stress. J Neurol Neurosurg Psychiatry. 1970;33:180-7.

26. Ellenberg U, Mattern T, Seddon PJ. Heart rate responses provide an objective evaluation of human disturbance stimuli in breeding birds. Conserv Physiol. 2013;1:cot013.

27. Wascher CA, Fraser ON, Kotrschal K. Heart rate during conflicts predicts post-conflict stress-related behavior in greylag geese. PLOS ONE. 2010:5:e15751.

28. Nimon AJ, Schroter RC, Oxenham RK. Artificial eggs: measuring heart rate and effects of disturbance in nesting penguins. Physiol Behav. 1996;60:1019-22

29. Lefcourt AM, Erez B, Varner MA, Barfield R, Tasch U. A noninvasive radiotelemetry system to monitor heart rate for assessing stress response of bovines. J Dairy Sci. 1999;82:1179-87.

30. MacArthur RA, Johnston RH, Geist V. Factors influencing heart rate in freeranging bighorn sheep: a physiological approach to the study of wild life harassment. Can J Zool. 1979;57:2010-21.

31. Laske TG, Harlow HJ, Garshelis DL, laizzo PA. Extreme respiratory sinus arrhythmia enables overwintering black bear survival — physiological insights and applications to human medicine. J Cardiovasc Transl Res. 2010;3:559-69.

32. Evans AL, Sahlén V, Støen OG, Fahlman Å, Brunberg S, Madslien K, Fröbert $\mathrm{O}$, Swenson JE, Arnemo JM. Capture, anesthesia, and disturbance of free-ranging brown bears (Ursus arctos) during hibernation. PLOS ONE. 2012:7:e40520

33. Støen OG, Ordiz A, Evans AL, Laske TG, Kindberg J, Fröbert O, Swenson JE, Arnemo JM. Physiological evidence for a human-induced landscape of fear in brown bears (Ursus arctos). Physiol Behav. 2015;152:244-8.

34. Iles TL, Laske TG, Garshelis DL, laizzo PA. Blood clotting behavior is innately modulated in Ursus americanus during early and late denning relative to summer months. J Exp Biol. 2017:220:455-9.

35. Echols KN, Vaughan MR, Moll HD. Evaluation of subcutaneous implants for monitoring American black bear cub survival. Ursus. 2004;15:172-81.

36. Nelson OL, Robbins CT. Cardiac function adaptations in hibernating grizzly bears (Ursus arctos horribilis). J Comp Physiol B. 2010;180:465-73.

37. Evans AL, Singh NJ, Friebe A, Arnemo JM, Laske TG, Frøbert O, Swenson JE, Blanc S. Drivers of hibernation in the brown bear. Front Zool. 2016:13:7.

38. Iles TL, Laske TG, Garshelis DL, Mattison L, Lee B, Eisele V, Gaassedelen E, laizzo PA. Medtronic Reveal LINQ ${ }^{\mathrm{TM}}$ devices provide better understanding of hibernation physiology in the American Black Bear (Ursus americanus). J Med Dev. 2017. https://doi.org/10.1115/DMD2017-3498.

39. Jørgensen PG, Arnemo JM, Swenson JE, Jensen JS, Galatius S, Frøbert O. Low cardiac output as physiological phenomenon in hibernating, free-ranging Scandinavian brown bears (Ursus arctos) — an observational study. Cardiovasc Ultrasound. 2014;12:36.

40. Farley SD, Robbins CT. Development of two methods to estimate body composition of bears. Can J Zool. 1994;72:220-6.

41. Ditmer MA, Vincent JB, Werden LK, Tanner JC, Laske TG, laizzo PA, Garshelis DL, Fieberg JR. Bears show a physiological but limited behavioral response to unmanned aerial vehicles. Curr Biol. 2015;25:2278-83.

42. Ditmer MA, Rettler SJ, Fieberg JR, laizzo PA, Laske TG, Noyce KV, Garshelis DL. American black bears perceive the risks of crossing roads. Behav Ecol. 2017:29:667-75.

43. O'Donoghue P, Rutz C. Real-time anti-poaching tags could help prevent imminent species extinctions. Journal of Applied Ecology. 2016;53:5-10. https://doi.org/10.1111/1365-2664.12452. 